\title{
Levantamento fitossociológico e produção de forragem em pasto de capim-gordura ${ }^{1}$
}

\author{
Márcia Vitória Santos ${ }^{2}$ Evander Alves Ferreira ${ }^{3}$, Dilermando Miranda da Fonseca ${ }^{4}$, Lino Roberto Ferreira ${ }^{5}$, \\ Leonardo David Tuffi Santos ${ }^{6}$, Daniel Valadão Silva ${ }^{*^{*}}$ \\ http://dx.doi.org/10.1590/0034-737X201562060008
}

\begin{abstract}
RESUMO
Este estudo foi realizado com o objetivo de efetuar o levantamento fitossociológico em um pasto de capimgordura (Melinis minutiflora P. Beauv.), que vinha sendo pastejado por bovinos de corte, há mais de dez anos, sem estratégia de manejo definida. A pesquisa foi desenvolvida no campus da Universidade Federal de Viçosa, em Viçosa, MG. Para avaliação das características fitossociológicas e da massa seca das plantas daninhas e da forrageira, utilizou-se o método do quadrado inventário, aplicando-se um quadrado de $0,25 \mathrm{~m}^{2}$, lançado, ao acaso, 40 vezes, na pastagem, perfazendo uma área amostral de $10 \mathrm{~m}^{2}$. Em toda a área experimental, foram identificadas 31 espécies e 12 famílias botânicas, tendo como destaque as famílias Poaceae, com oito espécies, e Asteraceae, com sete espécies. A forrageira cultivada M. minutiflora P.Beauv., corresponde a $24,26 \%$ da produção total de massa seca, entre espécies levantadas na área. Estes resultados indicam estádio avançado de degradação do pasto de capim-gordura, com elevada infestação por plantas daninhas, inclusive espécies consideradas tóxicas, epinescentes e de alta competitividade com as forrageiras, o que o caracteriza como pasto de baixa capacidade de suporte.
\end{abstract}

Palavras-chave: diversidade de espécies, forrageiras, pastagem degradada, plantas daninhas.

\section{ABSTRACT}

\section{Phytosociological survey and forage production in molasses grass pasture}

The objective of this study was the phytosociological survey in a pasture of molasses grass pasture (Melinis minutiflora P. Beauv.) that had been grazed by beef cattle over ten years without management. The survey was conducted in the campus of Federal University of Viçosa, MG. The phytosociological characteristics and dry mass of invasive species and the forage was evaluated using the inventory square method, using a $0.25 \mathrm{~m}^{2}$ squared frame randomly placed in 40 positions on the pasture, to make a sample area of $10 \mathrm{~m}^{2}$. A total of 31 species and 12 botany families were identified in the experimental area. The Poaceae family with eight species and Asteraceae with seven species were the most prominent families. The cultivated forage M. minutiflora P. Beauv. corresponded to $24.26 \%$ of the total dry mass of the species surveyed in the area. These results indicate an advanced stage of degradation of the molasses grass pasture with high weed infestation, including species that are considered toxic, spiny and highly competitive with the forage, characterizing a pasture of low support capacity.

Key words: species diversity, forage, degraded pasture, weeds.

\footnotetext{
Submetido em: 20/07/2014 e aprovado em:24/08/2015

'Parte da Tese de Doutorado da primeira autora, financiada pela FAPEMIG.

${ }^{2}$ Universidade Federal do Jequitinhonha e Mucuri, Departamento de Zootecnia, Diamantina, Minas Gerais, Brasil. marciavitori@hotmail.com

${ }^{3}$ Universidade Federal do Jequitinhonha e Mucuri, Departamento de Agronomia, Diamantina, Minas Gerais, Brasil. evanderalves@yahoo.com.br

${ }^{4}$ Universidade Federal de Viçosa, Departamento de Zootecnia, Viçosa, Minas Gerais, Brasil. dfonseca @ufv.br

Universidade Federal de Viçosa, Departamento de Fitotecnia, Viçosa, Minas Gerais, Brasil. lroberto@ufv.br

${ }^{6}$ Universidade Federal de Minas Gerais, Departamento de Agronomia, Diamantina, Minas Gerais, Brasil. Ituffi@ yahoo.com.br

${ }^{7}$ Universidade Federal de Viçosa, Departamento de Fitotecnia, Viçosa, Minas Gerais, Brasil.

*Autor para correspondência: danielvaladaos@yahoo.com.br
} 


\section{INTRODUÇÃO}

O capim-gordura (Melinis minutiflora P. Beauv.) é uma forrageira africana de baixo rendimento, naturalizada e adaptada aos solos ácidos e degradados, predominantes na região da Zona da Mata, no Estado de Minas Gerais, Brasil (Botrel et al., 1994). A degradação dessas pastagens está relacionada com o manejo inadequado, como queima, deficiência nutricional e alta taxa de lotação do pasto, tendo como consequência o aparecimento de plantas daninhas e a baixa cobertura do solo (Cóser et al., 1997; Vitor et al., 2008; Peron \& Evangelista, 2004).

A presença de plantas daninhas nas pastagens pode reduzir a produção e a qualidade da forrageira, além do risco de intoxicação do gado, por presença de plantas tóxicas. Todavia, o grau de interferência das plantas daninhas na pastagem depende da comunidade infestante (espécie, densidade e distribuição), da forrageira (cultivar, espaçamento e densidade), do ambiente (solo, clima e manejo) e do período de convivência (época e duração) (Pitelli, 1985; Blanco, 1972).

Um dos métodos mais utilizados no reconhecimento florístico, em áreas agrícolas, ou não, é o denominado estudo fitossociológico, que permite a determinação temporal e espacial da comunidade vegetal, obtendo-se dados de frequência, densidade, abundância e índice de importância relativa das espécies ocorrentes naquela formação (Erasmo et al., 2004).

O conhecimento do número de indivíduos e da distribuição das espécies encontradas em uma pastagem, por meio do levantamento fitossociológico, é de grande importância para auxiliar no manejo do pasto e na tomada de decisões, como a necessidade de recuperação e, ou, a renovação da pastagem. Vários são os trabalhos que buscam o conhecimento da flora infestante em pastagem, em diversas regiões no Brasil, buscando elucidar a intensidade de interferência (Peixoto et al., 1982; Mascarenhas et al., 1999, Modesto Júnior \& Mascarenhas, 2001; Silva \& Dias Filho, 2001; Lara et al., 2003; Tuffi Santos et al., 2004, Maciel et al., 2008, Galvão et al., 2011).

Ao se determinar a intensidade da interferência causada por populações de plantas daninhas sobre uma cultura, pode-se lançar mão de métodos de controle, especificamente quando a competição justificar economicamente sua aplicação (Galon et al., 2011). Por esta razão, esta pesquisa foi proposta com o objetivo de efetuar o levantamento fitossociológico de um pasto de capim-gordura, pastejado por bovinos de corte, há dez anos, sem estratégia de manejo definida, visando a determinar sua produção e seu estádio de degradação.

\section{MATERIAL E MÉTODOS}

O trabalho foi realizado no município de Viçosa-MG, Estado de Minas Gerais, Brasil, localizado a $20^{\circ} 45^{\prime}$ de latitude sul, $46^{\circ} 51^{\prime}$ ' de longitude oeste e a $689 \mathrm{~m}$ de altitude, em área de pasto pertencente ao Setor de Forragicultura, do Departamento de Zootecnia, da Universidade Federal de Viçosa.

A amostragem de solo da área experimental foi realizada em agosto de 2007, na camada de $0-20 \mathrm{~cm}$, sendo caracterizado como Latossolo Vermelho-Amarelo, de textura argilosa, com as seguintes características químicas: $\mathrm{pH}$ em $\mathrm{H}_{2} \mathrm{O}: 5,60$; $\mathrm{P}: 1,13 \mathrm{mg} \mathrm{dm}^{-3}$ (Mehlich) e $\mathrm{K}: 41,00 \mathrm{mg} \cdot \mathrm{dm}^{-3} ; \mathrm{Ca}^{+2}: 3,33 ; \mathrm{Mg}^{+2}: 0,57 \mathrm{e} \mathrm{Al}^{+3}: 0,03$ $\mathrm{cmol}_{\mathrm{c} .} \mathrm{dm}^{-3}\left(\mathrm{KCl} 1 \mathrm{~mol} \mathrm{~L}^{-1}\right)$, CTC (T): 5,99 $\mathrm{cmol}_{\mathrm{c}} \mathrm{dm}^{-3}$, soma de bases: $2,34 \mathrm{cmol}_{\mathrm{c} .} \mathrm{dm}^{-3}, \mathrm{H}+\mathrm{Al}: 3,65 \mathrm{cmol}_{\mathrm{c}} \mathrm{dm}^{-3} \mathrm{e}$ 2,37 dag. $\mathrm{kg}^{-1}$ de matéria orgânica e 20,35 de P-rem.

O levantamento fitossociológico foi realizado no mês de setembro de 2007, em pasto de capim-gordura (Melinis minutiflora P. Beauv.), mediamente ondulado, de aproximadamente $10.000 \mathrm{~m}^{2}$, que vinha sendo pastejado por bovinos de corte, por método de lotação contínua, há dez anos, sem estratégia de manejo definida. O clima da região, pelo sistema de Köppen (1948), é do tipo cwa, com estações seca (maio a outubro) e chuvosa (novembro a abril) bem definidas.

Para avaliar a infestação por plantas daninhas e a produção de forrageira, utilizou-se o método do quadrado inventário, aplicado por meio de um quadrado de 0,25 $\mathrm{m}^{2}$, lançado, ao acaso, 40 vezes, na pastagem, perfazendo uma área amostral de $10 \mathrm{~m}^{2}$. A cada lançamento, todas as espécies encontradas dentro do quadrado foram colhidas e devidamente identificadas e cadastradas, sendo registrado o número de indivíduos por espécie. A classificação adotada tomou como base o sistema Angiosperm Phylogeny Group II (APG, 2003), com auxílio nas delimitações das famílias e ordenamento de alguns gêneros, conforme Souza \& Lorenzi (2005). Entretanto, na identificação e quantificação das espécies também foi utilizada literatura específica (Kissmann \& Groth, 2000; Lorenzi, 2008), além de bibliografias sobre plantas medicinais, ornamentais, dissertações e teses relacionadas com o assunto.

Para fins práticos de identificação, adotou-se também a seguinte classificaçao: forrageira cultivada, demais forrageiras encontradas, plantas daninhas tóxicas, plantas daninhas epinescentes e demais plantas daninhas.

Foram estimados os parâmetros fitossociológicos: frequência absoluta (Fre abs) que permite avaliar a distribuição das espécies na área de estudo; densidade absoluta (Den abs), a quantidade de plantas de cada espécie por unidade de área; abundância absoluta (Ab abs) que informa sobre a concentração das espécies na área; 
frequência relativa (Fr), densidade relativa (Der) e abundância relativa (Abr) que informam a relação de cada espécie com as outras espécies encontradas na área; dominância relativa (Dor) expressa a dominância de cada espécie em relação à produção de biomassa por área; índice de valor de cobertura (IVC) que expressa a cobertura das espécies em relação a sua produção de biomassa e ao número de indivíduos por área; índice de valor de importância (IVI) que indica quais espécies são mais importantes dentro da área estudada, conforme as seguintes fórmulas (Concenço et al., 2013):

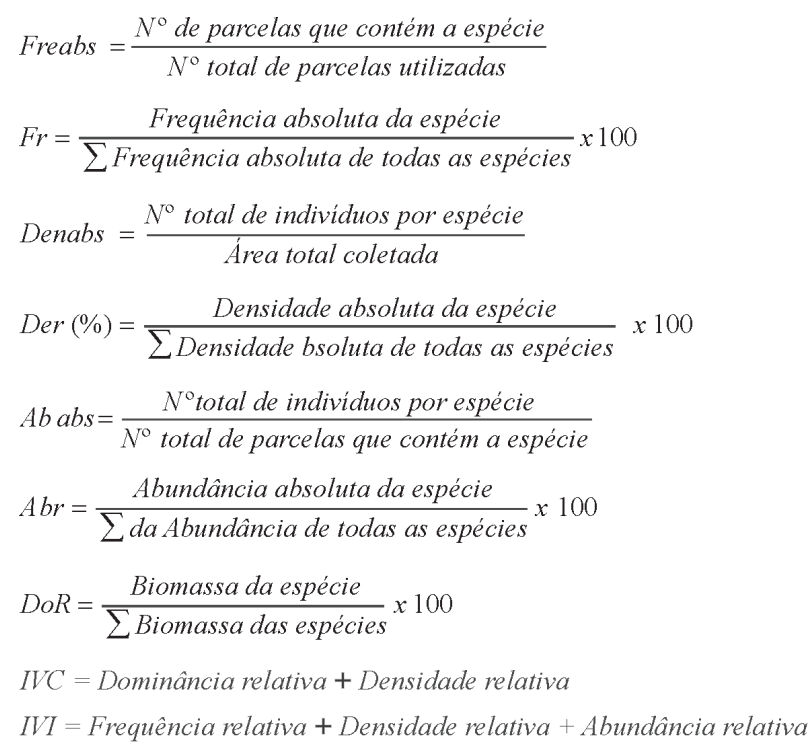

A cada amostragem, a parte aérea das plantas foi colhida rente ao solo e acondicionada em sacos plásticos. Após a colheita, cada amostra foi separada por espécies e levada à estufa com circulação forçada de ar, à temperatura de $60{ }^{\circ} \mathrm{C}$, por 72 horas, para determinação da massa seca.

\section{RESULTADOS E DISCUSSÃO}

Foram identificadas 12 famílias e 31 espécies, tendo como destaque as famílias Poaceae e Asteraceae, com oito e sete espécies, respectivamente (Tabela 1). Dentre as espécies da família Poaceae, além daquelas consideradas plantas daninhas de pastagens, como Andropogon bicornis L., Imperata brasiliensis Trin., Paspalum notatum Flüggé Parodi, foram também identificadas espécies de interesse forrageiro como Panicum maximum Jacq., Hyparrhenia rufa Nees. Stapf, Urochloa arrecta (Hack. ex T. Durand e Schinz) Stent e Urochloa decumbens (Stapf) R.D.Webster (Tabela 1), além da forrageira cultivada $M$. minutiflora.

As espécies que apresentaram maiores frequências foram: capim-gordura (M. minutiflora), tiriricão
(Cyperus esculentus L.), sapé (Imperata brasiliensis Trin.), guanxuma (Sida glaziovii K. Shumann) e matapasto (Campuloclinium macrocephalum Less) DC.), com valores de 0,$90 ; 0,85 ; 0,60 ; 0,45$ e 0,40 , respectivamente. Estas espécies também apresentaram os maiores valores de frequência relativa (Tabela 2), indicando grande ocorrência e competição em toda a pastagem de capim-gordura.

As espécies com maiores densidades e densidades relativas foram tiriricão, capim-gordura, sapé, guanxuma e capim-braquiária (Tabela 2). Esses resultados mostram ser o tiriricão a espécie com maior número de indivíduos na pastagem e entre todas as espécies observadas, o que expressa sua alta capacidade de infestação na pastagem.

Os maiores índices de abundância e abundância relativa foram observados nas espécies tiriricão, capim-gordura, guanxuma, grama-batatais (Paspalum notatum Flugge Parodi), sapé e fumo-bravo (Elephantopus mollis Kunth) (Tabela 2).

As espécies mais representativas na pastagem e seus respectivos valores de importância relativa (IVI) foram: tiriricão $(48,96 \%)$, capim-gordura $(35,63 \%)$, sapé $(20,24 \%)$, guanxuma $(19,13 \%)$, capim-braquiária $(10,73 \%)$ e mata-pasto $(10,47 \%)$ (Tabela 2$)$. Por estes resultados, observa-se que a forrageira cultivada na pastagem, M. minutiflora, não é a espécie com maior índice de valor de importância e isso se deve à grande frequência, abundância e densidade do tiriricão na pastagem. Dentre as espécies, tiriricão, sapé, guanxuma, capim-braquiária e mata-pasto, embora o tiriricao apresente maior índice de valor de cobertura $(28,53)$, possivelmente o capim-braquiária apresente maior capacidade competitiva com a forrageira capim-gordura, por produzir maior percentual de massa seca que as demais, apresentando maior dominância relativa $(18,53 \%)$ (Tabelas 2 e 3 ).

Embora a composição da comunidade de plantas daninhas em um agroecossistema esteja associada às condições edafoclimáticas da região, determinados manejos do solo e tratos culturais podem favorecer ou reprimir determinada espécie (Godoy et al., 1995). Em ecossistemas pastagens, a preferência de certas plantas pelos animais deve ser considerada, sendo que a herbivoria pode ocasionar um desbalanço da competição e o consequente favorecimento para espécies não aceitáveis pelos animais, como o tiriricão, o mata-pasto, guanxuma, sapé, fumo bravo e outras espécies encontradas neste estudo.

$\mathrm{Na}$ área de estudo, também foram observadas espécies leguminosas forrageiras, como amendoim forrageiro (Arachis pintoi Krapov. \& W.C.Greg.), carrapicho-beiço-de-boi (Desmodium adscendens (Sw.) 
D.C.) e soja perene (Neonotonia wightii (Graham ex Wight \& Arn.) J.A.Lackey) (Tabela 1). Mesmo que estas espécies apresentem baixo percentual de massa seca (Tabela 3), são de grande importância pelo potencial de fixação de $\mathrm{N}_{2}$ atmosférico, além do suprimento como forragem de elevado valor proteico, contribuindo para melhorar a qualidade da dieta dos animais.

Embora espécies como cambará (Lantana camara L.), samambaia (Pteridium aquilinum L. Kuhn) fedegoso (Senna obtusifolia (L.) H.S.Irwin \& Barneby) e fedegosinho (Senna occidentalis (L.) Link) apresentassem baixo Índice de Importância Relativa (IVI) (Tabela 2), deve-se atentar para sua presença, uma vez que apresentam ingredientes tóxicos, sendo maléficas aos animais quando consumidas, devendo ser controladas nas áreas de pastagens, mesmo quando em baixa ocorrência. Os percentuais de massa seca destas espécies na pastagem foram: cambará $(0,31)$, samambaia $(0,57)$, fedegoso $(2,95)$ e fedegosinho $(1,99)$ (Tabela 3$)$.
A intoxicação por samambaia ( $P$. aquilinum) é de grande ocorrência em todo o país, sendo a segunda causa mais importante de intoxicação por plantas, na Região Central do Rio Grande do Sul, correspondendo a $12 \%$ de todas as mortes causadas por plantas tóxicas em bovinos (Rissi et al. 2007).

A mimosinha (Mimosa pigra L.) é outra espécie que merece destaque, em razão da grande quantidade de espinhos em seus ramos, além da lobeira e do joá, também presentes na pastagem, que podem impedir o pastejo nas suas proximidades, ou, mesmo, ferir os animais. São comuns ferimentos no úbere de vacas em lactação, causados por plantas epinescentes, o que pode prejudicar a ordenha (Tuffi Santos et al., 2004), uma vez que podem levar a infecções que interferem na quantidade e na qualidade do leite. Esta espécie apresentou uma frequência de 3,07 e Índice de Importância Relativa de 6,04, com $4,66 \%$ de produção de massa seca, em relação às demais espécies presentes na pastagem.

Tabela 1: Famílias e espécies presentes no pasto de Melinis minutiflora, em Viçosa, MG

\begin{tabular}{|c|c|c|}
\hline \multirow{2}{*}{ Famílias } & \multicolumn{2}{|l|}{ Espécies } \\
\hline & Nome científico & Nome comum \\
\hline Poaceae & $\begin{array}{l}\text { Andropogon bicornis L. } \\
\text { Urochloa arrecta (Hack. ex T. Durand e Schinz) Stent } \\
\text { Urochloa decumbens (Stapf) R.D.Webster } \\
\text { Hyparrhenia rufa Nees. Stapf } \\
\text { Imperata brasiliensis Trin. } \\
\text { Melinis minutiflora } \text { P. Beauv. } \\
\text { Panicum maximum Jacq. } \\
\text { Paspalum notatum Flugge Parodi } \\
\text { Arachis pintoi Krapov. e Gregory } \\
\text { Desmodium adscendens (Sw.) D.C. }\end{array}$ & $\begin{array}{l}\text { rabo-de-burro } \\
\text { braquiária-do-brejo } \\
\text { capim-braquiária } \\
\text { jaraguá } \\
\text { sapé } \\
\text { capim-gordura } \\
\text { sempre-verde } \\
\text { grama batatais } \\
\text { amendoim forrageiro } \\
\text { carrapicho-beiço-de-boi }\end{array}$ \\
\hline Fabaceae & $\begin{array}{l}\text { Mimosa pigra L. } \\
\text { Neonotonia wightii (Wight e Arn.) J.A. } \\
\text { Senna obtusifolia } \text { L. H.S.Irwin \& Barneby } \\
\text { Senna ocidentalis } \text { L. Link } \\
\text { Baccharis trimera (Less.) DC } \\
\text { Bacharis dracunculifolia DC } \\
\text { Elephantopus mollis Kunth }\end{array}$ & $\begin{array}{l}\text { mimosinha } \\
\text { soja perene } \\
\text { fedegoso } \\
\text { fedegosinho } \\
\text { carqueja } \\
\text { alecrim-do-campo } \\
\text { fumo-bravo }\end{array}$ \\
\hline Asteraceae & $\begin{array}{l}\text { Campuloclinium macrocephalum Less) DC. } \\
\text { Campuloclinium maximilianii Schrad } \\
\text { Pterocaulon virgatum (L) DC } \\
\text { Vernonia polyanthes Less }\end{array}$ & $\begin{array}{l}\text { mata-pasto } \\
\text { mata-pasto rasteiro } \\
\text { barbasco } \\
\text { assa-peixe }\end{array}$ \\
\hline Commelinaceae & Commelina erecta $\mathrm{L}$. & Trapoeraba \\
\hline Cyperaceae & Cyperus esculentus L. & Tiriricão \\
\hline Lamiaceae & Hyptis suaveolens (L.) Poit & Cheirosa \\
\hline Verbenaceae & Lantana camara $\mathrm{L}$. & Cambará \\
\hline Polypodiaceae & Pteridium aquilinum L. Kuhn & Samambaia \\
\hline Polygonaceae & Rumex obtusifolius L. & língua-de-vaca \\
\hline Anacardiaceae & Schinus terebenthifolius Raddi & Aroeirinha \\
\hline Malvaceae & Sida glaziovii K. Shumann & Guanxuma \\
\hline Solanaceae & $\begin{array}{l}\text { Solanum lycocarpum St. Hill. } \\
\text { Solanum sisymbrifolium Lam. }\end{array}$ & $\begin{array}{l}\text { Lobeira } \\
\text { Joá }\end{array}$ \\
\hline
\end{tabular}


Foi observada uma distribuição agrupada das plantas daninhas com espinhos e tóxicas, nesta pastagem, o que facilita o controle localizado e direcionado para estas espécies problemáticas.

O percentual de massa seca de plantas de interesse forrageiro equivale a $56,46 \%$ do total de plantas encontradas na pastagem, sendo o restante $5,82 \%$ de plantas daninhas tóxicas, $5,80 \%$ de planta daninhas epinescentes e $31,92 \%$ das demais plantas daninhas identificadas na área.

Outras espécies problemáticas e seus respectivos percentuais de massa seca são o alecrim-do-campo (Baccharis dracunculifolia DC. - 6,64\%), o assa-peixe (Vernonia polyanthes Less - 6,33\%), a aroeirinha (Schinus terebinthifolius Raddi - 5,94\%) e o mata-pasto rasteiro (Campuloclinium maximilianii (Schrad. ex DC.) R.M.King \& H.Rob. - 2,59\%), bastante comuns na Zona da Mata de Minas Gerais, por apresentarem grande capacidade competitiva e serem de porte alto, sombreando as espécies forrageiras e limitando seu crescimento (Santos et al., 2006).

Em relação à massa seca das espécies identificadas, a produção total das plantas daninhas forrageiras (1.923 $\left.\mathrm{kg} \cdot \mathrm{ha}^{-1}\right)$ e não forrageiras $\left(2.600 \mathrm{~kg} \cdot \mathrm{ha}^{-1}\right)$ equivale a $75,74 \%$ do total de massa seca produzida (5.972 kg.ha-1). A espécie forrageira cultivada na área, $M$. minutiflora, corresponde a $24,26 \%$ da produção total das espécies (Tabela 3), o que representa alta infestação por plantas daninhas.

Segundo escala proposta por Nascimento Júnior et al., (1994), para classificação do estádio de degradação, em pastagens de $U$. decumbens, são consideradas pastagens razoáveis aquelas que apresentam 25 a $50 \%$ de braquiária na composição botânica e, pobres, as que apresentam percentagem da espécie forrageira inferior

Tabela 2: Valores de frequência absoluta (Fre abs), frequência relativa (Fr), densidade absoluta (Den abs), densidade relativa (Dr), abundância absoluta (Ab abs), abundância relativa (Abr), dominância relativa (Dor), índice de valor de cobertura (IVC) e índice de valor de importância (IVI), das espécies levantadas no pasto de Melinis minutiflora Beauv., em Viçosa, MG

\begin{tabular}{|c|c|c|c|c|c|c|c|c|c|}
\hline Espécies & $\begin{array}{l}\text { Fre } \\
\text { abs }\end{array}$ & $\begin{array}{c}\text { Fr } \\
(\%)\end{array}$ & $\begin{array}{c}\text { Den } \\
\text { abs }\end{array}$ & $\begin{array}{l}\text { Der } \\
(\%)\end{array}$ & $\begin{array}{c}\text { Aba } \\
\text { bs }\end{array}$ & $\begin{array}{l}\text { Abr } \\
(\%)\end{array}$ & $\begin{array}{l}\text { Dor } \\
(\%)\end{array}$ & IVC & IVI \\
\hline Andropogon bicornis $\mathrm{L}$. & 0,20 & 2,45 & 0,4 & 0,98 & 1,00 & 1,76 & 0,54 & 1,51 & 5,18 \\
\hline Arachis pintoi Krapov. e Gregory & 0,10 & 1,23 & 0,2 & 0,49 & 1,00 & 1,76 & 0,45 & 0,94 & 3,47 \\
\hline Baccharis trimera (Less.) DC & 0,15 & 1,84 & 0,4 & 0,98 & 1,33 & 2,34 & 0,14 & 1,12 & 5,16 \\
\hline Bacharis dracunculifolia DC & 0,30 & 3,68 & 0,7 & 1,71 & 1,17 & 2,05 & 6,64 & 8,35 & 7,44 \\
\hline Urochloa arrecta (Hack. ex T. Durand e Schinz) Stent & 0,25 & 3,07 & 1,1 & 2,68 & 2,20 & 3,86 & 0,19 & 2,87 & 9,61 \\
\hline Urochloa decumbens (Stapf) R.D.Webster & 0,35 & 4,29 & 1,3 & 3,17 & 1,86 & 3,26 & 18,53 & 21,70 & 10,73 \\
\hline Commelina erecta $\mathrm{L}$. & 0,05 & 0,61 & 0,1 & 0,24 & 1,00 & 1,76 & 0,95 & 1,19 & 2,61 \\
\hline Cyperus esculentus $\mathrm{L}$. & 0,85 & 10,43 & 11,1 & 27,07 & 6,53 & 11,46 & 1,46 & 28,53 & 48,96 \\
\hline Desmodium adscendens (Sw.) D.C. & 0,10 & 1,23 & 0,3 & 0,73 & 1,50 & 2,63 & 0,25 & 0,98 & 4,59 \\
\hline Elephantopus mollis Kunth & 0,20 & 2,45 & 1,1 & 2,68 & 2,75 & 4,83 & 0,29 & 2,98 & 9,96 \\
\hline Campuloclinium macrocephalum Less) DC. & 0,40 & 4,91 & 1,2 & 2,93 & 1,50 & 2,63 & 1,87 & 4,80 & 10,47 \\
\hline Campuloclinium maximilianii Schrad & 0,15 & 1,84 & 0,5 & 1,22 & 1,67 & 2,93 & 2,60 & 3,81 & 5,99 \\
\hline Hyparrhenia rufa Nees. Stapf & 0,25 & 3,07 & 1,1 & 2,68 & 2,20 & 3,86 & 5,15 & 7,84 & 9,61 \\
\hline Hyptis suaveolens (L.) Poit & 0,20 & 2,45 & 1,0 & 2,44 & 2,50 & 4,39 & 1,33 & 3,77 & 9,28 \\
\hline Imperata brasiliensis Trin. & 0,60 & 7,36 & 3,3 & 8,05 & 2,75 & 4,83 & 0,97 & 9,02 & 20,24 \\
\hline Lantana camara $\mathrm{L}$. & 0,25 & 3,07 & 0,6 & 1,46 & 1,20 & 2,11 & 0,31 & 1,77 & 6,64 \\
\hline Melinis minutiflora Beauv. & 0,90 & 11,04 & 7,2 & 17,56 & 4,00 & 7,02 & 24,26 & 41,82 & 35,63 \\
\hline Mimosa pigra $\mathrm{L}$. & 0,25 & 3,07 & 0,5 & 1,22 & 1,00 & 1,76 & 4,66 & 5,88 & 6,04 \\
\hline Neonotonia wightii (Wight e Arn.) J.A. & 0,35 & 4,29 & 1,1 & 2,68 & 1,57 & 2,76 & 0,99 & 3,67 & 9,74 \\
\hline Panicun maximum Jacq. & 0,25 & 3,07 & 0,7 & 1,71 & 1,40 & 2,46 & 6,64 & 8,34 & 7,23 \\
\hline Paspalum notatum Flugge Parodi & 0,10 & 1,23 & 0,6 & 1,46 & 3,00 & 5,27 & 0,61 & 2,07 & 7,96 \\
\hline Pteridium aquilinum L. Kuhn & 0,20 & 2,45 & 0,5 & 1,22 & 1,25 & 2,19 & 0,57 & 1,79 & 5,87 \\
\hline Pterocaulon virgatum $(\mathrm{L}) \mathrm{DC}$ & 0,10 & 1,23 & 0,3 & 0,73 & 1,50 & 2,63 & 0,92 & 1,66 & 4,59 \\
\hline Rumex obtusifolius L. & 0,05 & 0,61 & 0,1 & 0,24 & 1,00 & 1,76 & 0,43 & 0,67 & 2,61 \\
\hline Senna obtusifolia L. H.S.Irwin \& Barneby & 0,15 & 1,84 & 0,3 & 0,73 & 1,00 & 1,76 & 2,95 & 3,68 & 4,33 \\
\hline Senna ocidentalis L. Link & 0,05 & 0,61 & 0,1 & 0,24 & 1,00 & 1,76 & 1,99 & 2,24 & 2,61 \\
\hline Schinus terebenthifolius Raddi & 0,20 & 2,45 & 0,5 & 1,22 & 1,25 & 2,19 & 5,94 & 7,16 & 5,87 \\
\hline Sida glaziovii K. Shumann & 0,45 & 5,52 & 3,1 & 7,56 & 3,44 & 6,05 & 0,89 & 8,45 & 19,13 \\
\hline Solanum lycocarpum St. Hill. & 0,15 & 1,84 & 0,3 & 0,73 & 1,00 & 1,76 & 0,70 & 1,43 & 4,33 \\
\hline Solanum sisymbrifolium Lam. & 0,25 & 3,07 & 0,7 & 1,71 & 1,40 & 2,46 & 0,44 & 2,15 & 7,23 \\
\hline Vernonia polyanthes Less & 0,30 & 3,68 & 0,6 & 1,46 & 1,00 & 1,76 & 6,33 & 7,79 & 6,90 \\
\hline Total & 8,15 & 100 & 41 & 100 & 56,97 & 100 & 100 & 300 & 300 \\
\hline
\end{tabular}


a 25\%. Nesse contexto, extrapolando essa classificação para a pastagem de M. minutiflora, constata-se elevado nível de degradação pela baixa produção da forrageira cultivada e alta infestação por plantas daninhas.

Entretanto, considerando-se o percentual das demais plantas forrageiras presentes na pastagem, constata-se que esta apresenta um índice de produção de massa de forragem superior a $25 \%$, caracterizando-a como pastagem de média degradação. Todavia, a produção total de forragem é comprometida pela interferência das plantas daninhas, as quais representam $44 \%$ da produção de massa seca total da pastagem.

A infestação por plantas daninhas deve ser vista como consequência da falta de adaptação, vigor e competitivi-

Tabela 3: Massa seca (kg.ha-1) e percentual de capim-gordura (Melinis minutiflora Beauv.) de espécies de plantas daninhas forrageiras e não forrageiras, em pasto de capim-gordura, em Viçosa, MG, Brasil

\begin{tabular}{|c|c|c|c|}
\hline Espécies & Nomes comuns & Massa seca $\left(\mathrm{kg} . h a^{-1}\right)$ & $(\%)$ \\
\hline \multicolumn{4}{|c|}{ Forrageira Cultivada } \\
\hline Melinis minutiflora Beauv. & Capim-gordura & $1.449,00$ & 24,26 \\
\hline Total da forrageira cultivada & $1.449,00$ & 24,26 & \\
\hline \multicolumn{4}{|c|}{ Demais forrageiras encontradas na área } \\
\hline Urochloa arrecta (Hack. ex T. Durand e Schinz) Stent & Braquiária-do-brejo & 11,30 & 0,19 \\
\hline Urochloa decumbens (Stapf) R.D.Webster & capim-braquiária & $1.106,80$ & 18,53 \\
\hline Hyparrhenia rufa Nees. Stapf & jaraguá & 307,70 & 5,15 \\
\hline Panicum maximum Jacq. & Sempre-verde & 396,30 & 6,64 \\
\hline Arachis pintoi Krapov. e Gregory & amendoim forrageiro & 27,00 & 0,45 \\
\hline Desmodium adscendens (Sw.) D.C. & Carrapicho-beiço-de-boi & 15,00 & 0,25 \\
\hline Neonotonia wightii (Wight e Arn.) J.A. & soja perene & 58,90 & 0,99 \\
\hline Total de outras plantas forrageiras & $1.923,00$ & 32,20 & \\
\hline \multicolumn{4}{|c|}{ Plantas daninhas tóxicas } \\
\hline Lantana camara $\mathrm{L}$. & cambará & 18,50 & 0,31 \\
\hline Pteridium aquilinum L. Kuhn & samambaia & 34,20 & 0,57 \\
\hline Senna obtusifolia L. H.S.Irwin \& Barneby & fedegoso & 176,00 & 2,95 \\
\hline Senna ocidentalis L. Link & fedegosinho & 119,00 & 1,99 \\
\hline Total de plantas Tóxicas & - & 347,70 & 5,82 \\
\hline \multicolumn{4}{|c|}{ Plantas epinescentes } \\
\hline Mimosa pigra $\mathrm{L}$. & Mimosinha & 278,50 & 4,66 \\
\hline Solanum lycocarpum St. Hill. & Lobeira & 42,00 & 0,70 \\
\hline Solanum sisymbrifolium Lam. & Joá & 26,40 & 0,44 \\
\hline Total de plantas epinescentes & & 346,90 & 5,80 \\
\hline \multicolumn{4}{|c|}{ Demais plantas daninhas } \\
\hline Andropogon bicornis $\mathrm{L}$. & rabo-de-burro & 32,20 & 0,54 \\
\hline Imperata brasiliensis Trin. & Sapé & 58,00 & 0,97 \\
\hline Paspalum notatum Flugge Parodi & Grama batatais & 36,50 & 0,61 \\
\hline Baccharis trimera (Less.) DC & Carqueja & 8,40 & 0,14 \\
\hline Bacharis dracunculifolia DC & Alecrim-do-campo & 396,70 & 6,64 \\
\hline Elephantopus mollis Kunth & fumo-bravo & 17,60 & 0,30 \\
\hline Campuloclinium macrocephalum Less) DC. & mata-pasto & 111,70 & 1,87 \\
\hline Campuloclinium maximilianii Schrad & mata-pasto rasteiro & 155,00 & 2,59 \\
\hline Pterocaulon virgatum (L) DC & Barbasco & 55,20 & 0,92 \\
\hline Vernonia polyanthes Less & Assa-peixe & 378,00 & 6,33 \\
\hline Commelina erecta $\mathrm{L}$. & Trapoeraba & 56,80 & 0,95 \\
\hline Cyperus esculentus L. & Tiriricão & 86,90 & 1,46 \\
\hline Hyptis suaveolens (L.) Poit & Cheirosa & 79,30 & 1,33 \\
\hline Rumex obtusifolius L. & Língua-de-vaca & 25,60 & 0,43 \\
\hline Schinus terebenthifolius Raddi & Aroeirinha & 354,70 & 5,95 \\
\hline Sida glaziovii K. Shumann & Guanxuma & 53,00 & 0,89 \\
\hline Total das demais plantas daninhas & & $1.905,60$ & 31,92 \\
\hline Total Geral & - & $5.972,20$ & 100,00 \\
\hline
\end{tabular}

Rev. Ceres, Viçosa, v. 62, n.6, p. 561-567, nov-dez, 2015 
dade das espécies forrageiras utilizadas, bem como falta de práticas de manejo apropriadas. Por isso, faz-se necessário o manejo correto do pasto, desde a formação da pastagem, pela escolha correta da espécie forrageira, preparo do solo, semeadura em época adequada, quantidade e profundidade recomendadas, correção e adubação do solo, no estabelecimento da pastagem, de acordo com a exigência da forrageira, bem como o manejo adequado após a formação do pasto.

Uma vez detectada alta infestação por plantas daninhas na pastagem e baixa produção da espécie forrageira cultivada, como observado nesta área estudada, é necessária sua renovação, visando a otimizar a produtividade pecuária.

\section{CONCLUSÕES}

O pasto de capim-gordura é infestado por várias espécies e famílias de plantas daninhas, inclusive espécies consideradas tóxicas, epinescentes e de alta competitividade com as plantas forrageiras, que o caracteriza como pasto degradado, com baixo potencial de produção pecuária, necessitando de renovação.

\section{AGRADECIMENTOS}

Os autores agradecem ao Conselho Nacional de Desenvolvimento Científico e Tecnológico (CNPq), à Fundação de Amparo à Pesquisa do Estado de Minas Gerais (FAPEMIG) e à Coordenação de Aperfeiçoamento de Pessoal de Nível Superior (CAPES), pelo financiamento e suporte para a execução do trabalho.

\section{REFERÊNCIAS}

APG II (2003) An update of the Angiosperm Phylogeny Group classification for the orders and families of flowering plants: APG II. Botanical Journal of the Linnean Society, 141:399-436.

Blanco HGA (1972) Importância dos estudos ecológicos nos programas de controle de plantas daninhas. Biológico, 38:343-350.

Botrel MA, Alvim MJ, Xavier DF \& Salvati JA (1994) Avaliação de forrageiras em dois municípios do Campo das Vertentes de Minas Gerais. Revista da Sociedade Brasileira de Zootecnia, 23:189-96.

Concenço G, Tomazi M, Correia IVT, Santos SA \& Galon L (2013) Phytosociological surveys: tools for weed science? Planta Daninha, 31:469-482.

Cóser AC, Cruz Filho AB, Martins CE, Carvalho LA, Alvim MJ \& Freitas VP (1997) Desempenho animal em pastagem de capim-gordura e braquiária. Pasturas Tropicales, 19:14-19.

Erasmo EAL, Pinheiro LLA \& Costa NV (2004) Levantamento fitossociológico das comunidades de plantas infestantes em áreas de produção de arroz irrigado cultivado sob diferentes sistemas de manejo. Planta daninha, 22:195-201.

Galon L, Tironi SP, Faria AT, Silva AF, Silva AA, Concenço G, Borges ET, Rocha PRR, Ferreira EA \& Aspiazú I (2011) Interferência da Urochloa brizantha nas características morfológicas da cana-de-açúcar. Planta daninha, 29:1029-1036.
Galvão AKL, Silva JF, Albertino SMF, Monteiro GPF \& Calvacante DP (2011) Levantamento fitossociológico em pastagens de várzea no Estado do Amazonas. Planta daninha, 29:69-75.

Godoy G, Vega J \& Pitty A (1995) El tipo de labranza afecta la flora y la distribución vertical del banco de semillas de malezas. Ceiba, 36:217229.

Kissmann KG \& Groth D (2000) Plantas infestantes e Nocivas: Tomo III. $2^{a}$ ed. São Paulo, BASF. 722p.

Koppen W (1948) Climatologia com un estudio de los climas de la tierra. México, Fondo de Cultura Economica. 478p.

Lara JFR, Macedo JF \& Brandão M (2003) Plantas daninhas em pastagens de várzeas do estado de Minas Gerais. Planta Daninha, 21:11-20.

Lorenzi H (2008) Plantas daninhas do Brasil: terrestres, aquáticas, parasitas e tóxicas. $4^{\mathrm{a}}$ ed. Nova Odessa, Plantarum. 640p.

Maciel CDG, Poletini JP, Aquino CJR, Ferreira DM \& Maio RMD (2008) Composição florística da comunidade infestante em gramados de $P$. notatum no município de Assis, SP. Planta Daninha, 26:57-64.

Mascarenhas REB, Modesto Júnior MS, Dutra S, Souza Filho APS \& Neto JFT (1999) Plantas daninhas de uma pastagem cultivada de baixa produtividade no Nordeste Paraense. Planta daninha, 17:399-418.

Modesto Júnior MS \& Mascarenhas REB (2001) Levantamento da infestação de plantas daninhas associada a uma pastagem cultivada de baixa produtividade no nordeste paraense. Planta Daninha, 19:11-21.

Nascimento Júnior D, Queiroz DS \& Santos MVF (1994) Degradação das pastagens e critérios para avaliação. In: Peixoto AM, Moura JC \& Faria VP (Eds.) $11^{\circ}$ Simpósio sobre Manejo de Pastagem, Piracicaba. Anais, FEALQ. 325p.

Peixoto AL, Carvalho SM \& Da Rosa MMT (1982) Análise botânica de um campo de pastagem no estado do Rio de Janeiro. Planta Daninha, $5: 1-7$.

Peron AJ \& Evangelista AR (2004) Degradação de pastagens em regiões de cerrado, Ciência e Agrotecnologia, 28:655-661.

Pitelli RA (1985) Interferência de plantas daninhas em culturas agrícolas. Informe Agropecuário, 11:16-27.

Rissi DR, Rech RR, Pierezan F, Gabriel AL, Trost ME, Brum JS, Kommers GD \& Barros CSL (2007) Intoxicação por plantas e micotoxinas associadas a plantas em bovinos no Rio Grande do Sul. Pesquisa Veterinária Brasileria, 27:261-268.

Santos MV, Freitas FCL, Ferreira FA, Viana RG, Tuffi Santos LD \& Fonseca DM (2006) Eficácia e persistência no solo de herbicidas utilizados em pastagem. Planta Daninha, 24:391-398.

Silva DSM \& Dias-Filho MB (2001) Banco de sementes de plantas daninhas em solo cultivado com pastagens de Urochloa brizantha e Urochloa humidicola de diferentes idades. Planta Daninha, 19:1852001.

Souza VC \& Lorenzi H (2005) Botânica sistemática: guia ilustrado para identificação das famílias de angiospermas da flora brasileira, baseado em APG II. 1.ed. Nova Odessa, Plantarum. 640p.

Tuffi Santos LD, Santos IC, Oliveira CH, Santos MV, Ferreira FA \& Queiroz DS (2004) Levantamento fitossociológico em pastagens degradadas sob condições de várzea. Planta Daninha, 22:343-349.

Vitor CMT, Fonseca DM, Moreira LM, Fagundes JL, Nascimento Junior D, Ribeiro Junior JI \& Pereira AL (2008) Rendimento e composição química do capim-braquiária introduzido em pastagem degradada de capim-gordura. Revista Brasileira de Zootecnia, 37:2107-2114. 